\title{
Prevalence of Bartonella henselae and Bartonella clarridgeiae in cats in the south of Brazil: a molecular study
}

\author{
Rodrigo Staggemeier ${ }^{1 /}$, Carolina Augusto Venker ${ }^{1}$, Deisy Heck Klein², Mariana Petry ${ }^{2}$, \\ Fernando Rosado Spilki', Vlademir Vicente Cantarelli ${ }^{1}$
}

'Laboratório de Biomedicina, Universidade Feevale, RS-239 2755, 93352-000 Novo Hamburgo, RS, Brasil

${ }^{2}$ Centro de Proteção aos Animais, Novo Hamburgo, RS, Brasil

Bartonella spp are the causative agent of cat scratch disease in humans. Cats are the natural reservoir of these bacteria and may infect humans through scratches, bites or fleas. Blood samples from 47 cats aged up to 12 months were collected for this study. All animals were lodged in municipal animal shelters in the Vale do Sinos region, Rio Grande do Sul, Brazil. Bartonella spp were detected by genus-specific polymerase chain reaction (PCR) and when the PCR was positive, the species were determined by DNA sequencing. A Giemsa-stained blood smear was also examined for the presence of intraerythrocytic elements suggestive of Bartonella spp infection. Phylogenetic analysis was also performed for all positive samples. Using molecular detection methods, Bartonella spp were detected in $17.02 \%$ (8/47) of the samples. In seven out of eight samples confirmed to be positive for Bartonella spp, blood smear examination revealed the presence of intraerythrocytic elements suggestive of Bartonella spp. Phylogenetic analysis characterized positive samples as Bartonella henselae (5) or Bartonella clarridgeiae (3). To the best of our knowledge, this is the first molecular study demonstrating the presence of Bartonella spp in cats from the Southern Region of Brazil.

Key words: Bartonella - cats - cat scratch disease - Rio Grande do Sul

Bartonella spp are small, Gram-negative, pleomorphic, fastidious, hemotropic bacteria that infect humans in addition to domestic and wild mammals (Angulo et al. 1994) and they are considered emergent infectious agents (Spach \& Koehler 1998, Dehio \& Sander 1999). Human infections by Bartonella spp are endemic in some South American countries, such as Peru, Ecuador and Colombia (Maco et al. 2004). Today, more than 23 species are recognized within this genus (Lamas et al. 2008) and, among these, 13 species are related to human diseases (Jacomo et al. 2002), especially Bartonella bacilliformis, Bartonella quintana, Bartonella henselae, Bartonella elizabethae (Anderson \& Neuman 1997) and Bartonella clarridgeiae (Kordick et al. 1997).

Bartonella spp have different arthropod vectors, such as fleas (Ctenocephalides felis), lice (Pediculus humanus corporis), sandflies (Lutzomyia verrucarum, Lutzomyia peruensis) (Jacomo et al. 2002) and ticks (Ixodes pacificus) (Chang et al. 2001, Cotté et al. 2008). The main animal reservoirs for these bacteria are cats, dogs and rodents (Jacomo et al. 2002) and contact with vectors and cat scratches are the most significant modes of transmission (Carithers 1985).

In both humans and domestic animals, infection with Bartonella may be asymptomatic and can resolve spontaneously without any treatment; however, in some cas-

Financial support: Biomedical Laboratory/FEEVALE

+ Corresponding author: rstaggemeier@gmail.com

FRS is CNPq Research Productivity Fellow - Level 2.

Received 10 April 2010

Accepted 12 August 2010 es, the disease may be fatal if left untreated (Jacomo et al. 2002). Historically, the most frequently diagnosed bartonellosis diseases are Carrion's disease (B. bacilliformis) (Maguiña et al. 2001), trench fever (B. quintana) (Spach et al. 1995) and, more recently, cat scratch disease (CSD) (B. henselae and B. clarridgeiae) (Lamas et al. 2008). Bartonella spp infect humans and can cause chronic bacteremia, which may be followed by fever, endocarditis, sepsis and neurological, psychiatric, ophthalmological, bone and hematologic manifestations, among others (Boulouis et al. 2005). The peak incidence of clinical manifestations is seen in children and young adults, aged between 2-14 years old (Anderson \& Neuman 1997). The first signs and symptoms of CSD may appear one to two weeks after exposure, though symptoms can take several months to appear. The specific symptoms are directly related to the species involved (Carithers 1985).

$B$. henselae is known to be the causative agent of CSD, which is characterized by benign chronic lymphadenopathy (Lamas et al. 2008) and, in some cases, Parinaud oculoglandular syndrome, encephalopathy, convulsions, endocarditis, hepatosplenomegaly, glomerulonephritis, pleurisy, mediastinal adenopathy, nodules in the head of the pancreas, osteomyelitis, atypical pneumonia, mammary tumours, haemolytic anaemia and eosinophilic purpura (Boulouis et al. 2005). In addition to CSD, this pathogen can cause bacillary angiomatosis, which is observed mainly in patients with immunodeficiencies (Boulouis et al. 2005). Several studies have demonstrated that cats are the main reservoir of $B$. henselae (Jacomo et al. 2002) and this species has the ability to infect the erythrocytes of felines (Kordick \& Breitschwerdt 1995). Transmission of these bacteria to humans occurs through bites or scratches of infected cats or by 
their fleas (C. felis) (Chomel 2000). It has been reported that most patients suffering from CSD were scratched or bitten by kittens or cats younger than 12 months of age (Zangwill et al. 1993). Similarly to B. henselae, B. clarridgeiae has been reported as a possible cause of CSD (Kordick et al. 1997) and it is also found in and transmitted by infected cats (Breitschwerdt \& Kordick 2000).

Laboratory diagnosis of bartonellosis may be difficult. The currently available techniques include blood smears (Billeter et al. 2008), culturing (Brenner et al. 1997, La Scola \& Raoult 1999), serology (Boulouis et al. 2005) and molecular biology (Jensen et al. 2000). Samples commonly used for analysis are blood, tissue fragments and secretions collected from lesions (Billeter et al. 2008).

The main objective of this study was to investigate the presence of Bartonella spp in cats, using molecular analysis of blood samples.

\section{MATERIALS AND METHODS}

Blood samples of 47 cats from two municipal animal shelters [Centro Municipal de Proteção aos Animais,

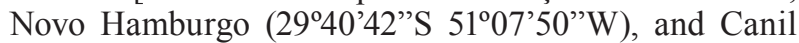

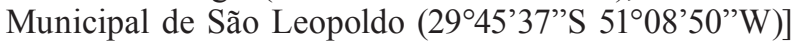
were collected during the period from August-October in 2009. The animals' ages varied between 6-12 months old, as determined by the size and the dentition of the cats. Young cats were chosen because infection by Bartonella spp is more common in young animals (Zangwill et al. 1993). Blood samples (5 mL) were collected by puncturing the internal jugular vein after application of a combination of xylazine and ketamine $(0.2 \mathrm{mg} / \mathrm{kg}$ each) as an anaesthetic. Blood samples were transferred to sample tubes containing ethylenediamine tetraacetic acid as the anticoagulant agent. Then, the samples were aliquoted into small plastic vials $(500 \mu \mathrm{L})$ and then kept frozen at $-20^{\circ} \mathrm{C}$ until needed for the molecular analyses.

Giemsa blood smears - Blood smears and Giemsa staining were performed essentially as described by Bentzel et al. (2008). After smearing and drying, the glass slides were covered with $96 \%$ ethyl alcohol for $2 \mathrm{~min}$ and then they were stained with Giemsa for $8 \mathrm{~min}$. After staining, the slides were washed briefly with distilled water and then dried at room temperature. The slides were analyzed by optical microscopy (1000X).

Molecular detection-DNA was extracted from $200 \mu \mathrm{L}$ of total blood using the QIAamp Kit (Qiagen ${ }^{\circledR}$ ) as recommended by the manufacturer. To monitor the extraction process for any foreign DNA contamination, a negative DNA extraction control, consisting of $200 \mu \mathrm{L}$ of sterile phosphate buffered saline ( $\mathrm{pH}$ 7.2), was included in each batch of samples that was processed. The primers used for the polymerase chain reaction (PCR) were BARTON-1 (5'-TAACCGATATTGGTTGTGTTGAAG-3') and BARTON-2 (5'-TAAAGCTAGAAAGTCTGGCAACATAACG-3'), which are specific for the Bartonella genus and target a fragment of the riboflavin synthase $\mathrm{C}$ gene of the bacteria. The PCR reactions were essentially performed as described previously (Johnson et al. 2003) with the following modifications: an initial denaturation of $5 \mathrm{~min}$ at $95^{\circ} \mathrm{C}$, followed by 37 cycles consist- ing of denaturation at $96^{\circ} \mathrm{C}$ for $20 \mathrm{~s}$, annealing at $55^{\circ} \mathrm{C}$ for $30 \mathrm{~s}$ and elongation at $72^{\circ} \mathrm{C}$ for $1 \mathrm{~min}$ and a final incubation for $3 \mathrm{~min}$ at $72^{\circ} \mathrm{C}$. A negative control, consisting of distilled water and positive control, consisting of extracted DNA from a blood sample known to contain B. bacilliformis (kindly provided by Alexander von Humboldt, Tropical Medicine Institute, Universidad Peruana Cayetano Heredia, Peru), were used in each PCR run. Following amplification, $5 \mu \mathrm{L}$ of each PCR reaction was subjected to electrophoresis on a 3\% agarose gel containing ethidium bromide. The presence of DNA fragments, indicating a positive reaction, was detected under a ultraviolet transilluminator $(B$. henselae 588 bp, B. clarridgeiae 585 bp). Positive samples were submitted to direct sequencing after the PCR products were purified with an AccuPrep(R) PCR Purification Kit (Bioneer), as directed by the package insert. Direct sequencing was performed using an ABI PRISM Dye TM Terminator Cycle Sequencing Ready Reaction kit (Big Dye - Applied Biosystems, Inc, USA), following the manufacturer's instructions, and electrophoresis was performed using an ABI 3110 automatic sequencer (Applied Biosystems, Inc, USA). The nucleotide sequences were submitted to analysis by BLAST at the DDBJ website (DNA Databank of Japan) and the results were used to confirm the genus and species of Bartonella.

Phylogenetic analysis was performed and the evolutionary relationships for the eight obtained sequences were inferred by comparing the obtained sequences with 54 nucleotide sequences from different Bartonella species found in GenBank, using the neighbor-joining method (Saitou \& Nei 1987). The evolutionary distances were computed using the Kimura 2-parameter method (Kimura 1980) and are expressed in units of the number of base substitutions per site. All positions containing gaps and missing data were eliminated from the dataset (complete deletion option). Phylogenetic analysis was conducted using the computer program MEGA4 (Tamura et al. 2007). The nucleotide sequences obtained were submitted to GenBank and deposited with the accesses HM588655-HM588662.

This study was approved by the Ethical Committee of Feevale University, protocol 2.12.03.09.1391, and cats were handled according to the recommendations and laws regarding the maintenance of animal welfare.

\section{RESULTS}

In this study, a PCR reaction using Bartonella genusspecific primers was used to evaluate the presence of DNA from Bartonella spp in blood samples from 47 cats. Using this method, eight samples were positive for Bartonella DNA, representing a $17.02 \%(8 / 47)$ positivity rate (Fig. 1) and all positive samples were confirmed to be Bartonella spp by direct sequencing of the PCR products.

Phylogenetic analysis of the sequences obtained from these positive samples clearly demonstrated that five sequences belonged to $B$. henselae and three corresponded to $B$. clarridgeiae, representing prevalences of $10.63 \%$ (5/47) and 6.38\% (3/47), respectively (Fig. 2).

Using Giemsa-stained blood smears, the presence of intraerythrocytic corpuscles suggesting Bartonella in- 


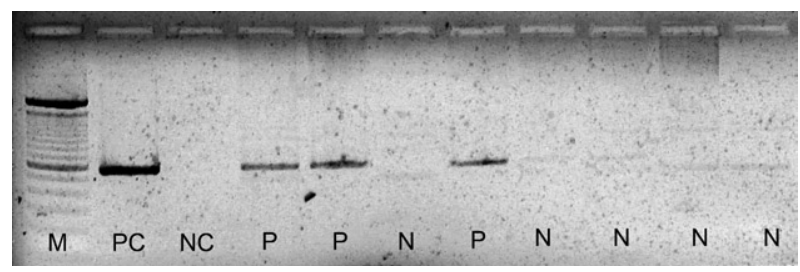

Fig. 1: photo produced polymerase chain reaction for identification of the genus Bartonella. M: molecular mass marker, 100 bp (Invitrogen); $\mathrm{N}$ : negative sample; $\mathrm{NC}$ : negative control; $\mathrm{P}$ : positive sample for the genus Bartonella; PC: positive control, Bartonella bacilliformis strain.

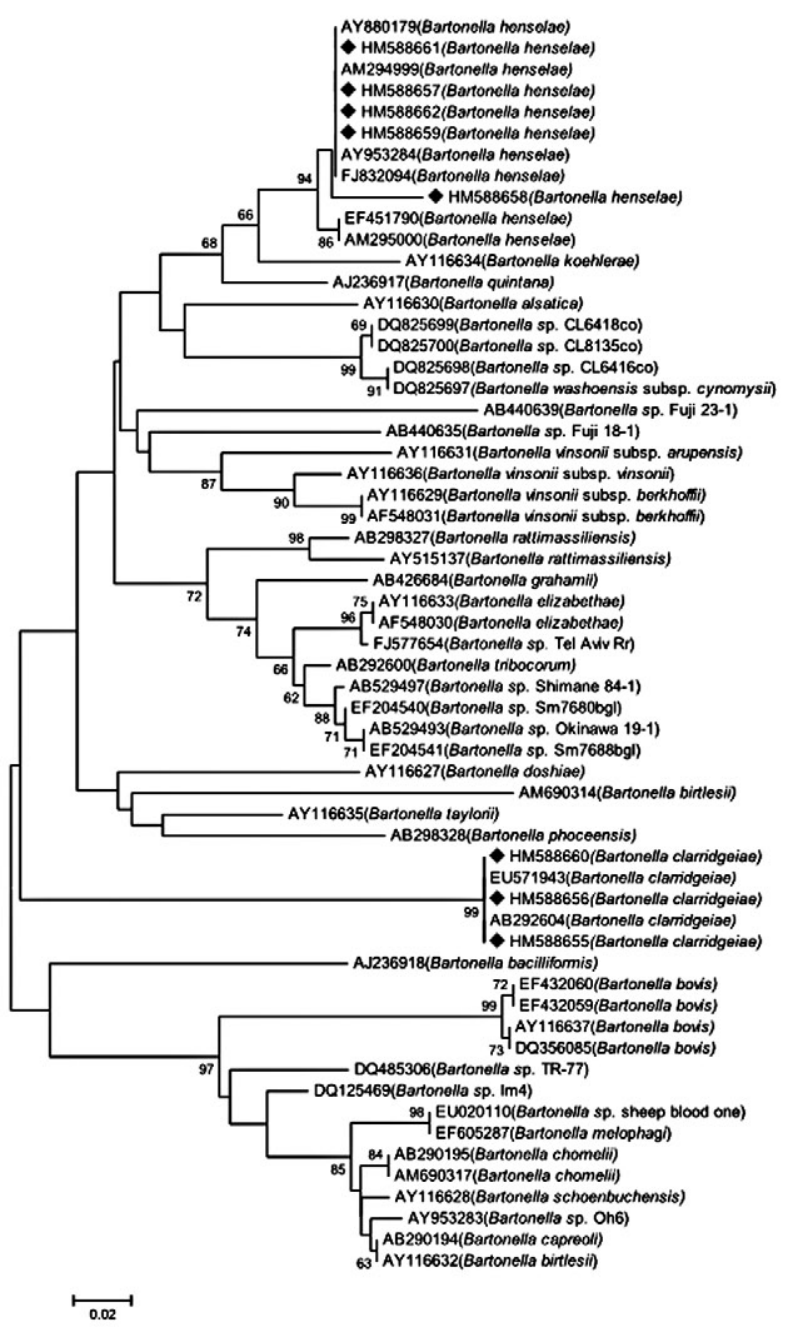

Fig. 2: evolutionary relationships of Bartonella isolated from stray cats from Vale dos Sinos, Rio Grande do Sul (diamonds), to other worldwide distributed strains. Bootstrap values are shown on branches.

fection were seen in seven out of the eight PCR-confirmed samples of Bartonella spp-containing blood (Fig. 3A, B). Only one PCR-positive sample had no visible corpuscles inside the erythrocytes. Overall, the sensitivity of the direct smear observation was considered to be $87.5 \%$ (7/8).

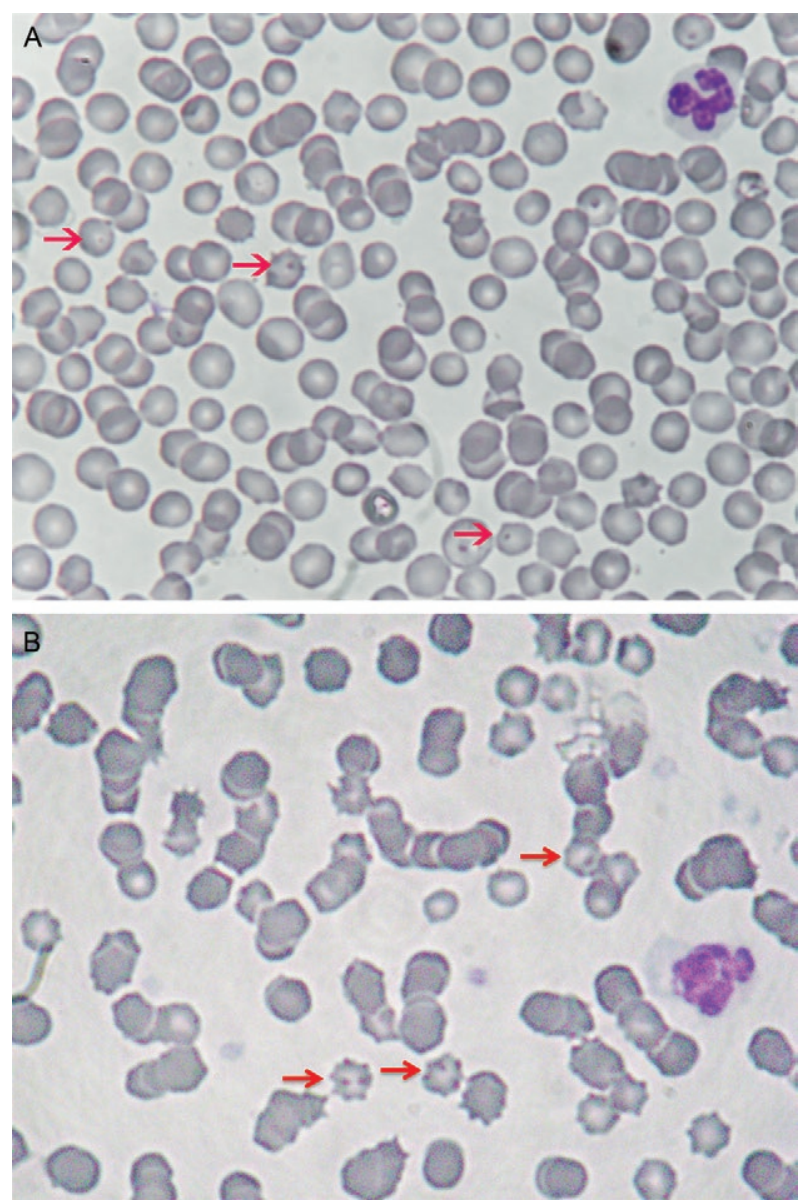

Fig. 3A: intraerythrocytic corpuscles compatible with Bartonella with coloration ranging from lilac-blue; B: erythrocytes housing multiple bacteria characterized by the presence of intraerythrocytic corpuscles.

\section{DISCUSSION}

To the best of our knowledge, this is the first molecular study of Bartonella in cats from the Southern Region of Brazil. Cats are considered the main zoonotic reservoir of B. henselae and B. clarridgeiae (Anderson \& Neuman 1997, Kordick et al. 1997) and are responsible for CSD as well as other Bartonella-associated diseases. Other authors have already demonstrated the occurrence of CSD (Amaro et al. 1996, Curi et al. 2006) and endocarditis (Lamas et al. 2007) caused by Bartonella spp in Brazil. In addition, the presence of these microorganisms has been reported in Minas Gerais (Costa et al. 2005), Rio de Janeiro (RJ) (Souza 2009, Lamas et al. 2010) and São Paulo (SP) (Filoni et al. 2006).

In this study, two techniques were performed in parallel for the detection of bacteria in the blood samples collected from cats in the south of Brazil. Using molecular methods, a prevalence of $17.02 \%$ for Bartonella spp was found, which can be considered high and correspond to a theoretical presence of Bartonella spp in about two out of 10 cats kept in shelters in our region. This result is similar to those of other studies performed in others parts of the world using similar molecular 
methods (PCR), including Italy (18\%) (Fabbi et al. 2004), Holland (22\%) (Bergmans et al. 1997), France (16.5\%) (Gurfield et al. 2001) and Thailand (16.3\%) (Inoue et al. 2009). However, the prevalence described here is lower than that shown in other reports, including reports from South Korea (33.3\%) (Kim et al. 2009) and Brazil (RJ, 90\%) (Souza 2009), both of which used molecular studies similar to ours, as well as reports from the Philippines (61\%) (Chomel et al. 1999) or even in other regions of Brazil (SP, 46\%) (Slhessarenko et al. 1996). These other studies were based on serological methods, which were used to detect anti-Bartonella antibodies, thus detecting not only active infection but also any past infection that resulted in antibody production. It is noteworthy that our data reflect the prevalence of Bartonella spp in cats, kept in animal shelters, where crowded conditions may increase the chance of bacterial spread due to close contact between healthy and previously infected animals. Therefore, these results cannot be extrapolated to household cats or pets. In Brazil, Bartonella spp were also found to be associated with dogs, although the prevalence (3.6\%) was found to be lower than that found in cats (Diniz et al. 2007). Whether dogs represent a risk for in terms of spreading the infection to humans or other animals remains to be determined.

In our study, $B$. henselae was detected in $10.63 \%$ of the blood samples, a prevalence rate similar to those found in molecular studies in other countries, such as Switzerland (8.3\%) (Glaus et al. 1997), the Czech Republic (8\%) (Melter et al. 2003), Turkey (8.2\%) (Celebi et al. 2009), Japan (9.1\%) (Maruyama et al. 1998), the United Kingdom (9.4\%) (Birtles et al. 2002) and Germany (13\%) (Sander et al. 1997). On the other hand, this prevalence rate was higher than those observed in Sweden (2.2\%) (Engvall et al. 2003) and Portugal (6.7\%) (Childs et al. 1995); the reason for these discrepancies is not clear. Compared with the results of molecular methods, seroprevalence results for $B$. henselae are usually higher: United States (39.5\%) (Chomel et al. 1995), Canada (17.8\%) (Leighton et al. 2001), Denmark (22.6\%) (Chomel et al. 2002), Poland (86\%) (Podsiadly et al. 2003), Indonesia (54\%) (Marston et al. 1999) and Singapore (47.5\%) (Nasirudeen \& Thong 1999).

B. clarridgeiae was detected in $6.38 \%$ of our samples and, to the best of our knowledge, this is the first description of this species in cats in Brazil. Our detection rate was higher than that reported in Germany (1\%) (Arvand et al. 2001), Turkey (1.2\%) (Celebi et al. 2009) and France (2\%) (Rolain et al. 2004) but lower than that of other countries, such as France (16\%) (Heller et al. 1997) and Indonesia (61\%) (Chomel et al. 1999), both of which used serology methods.

Giemsa-stained smears suggested the presence of an intraerythrocytic infection in seven out of eight PCRconfirmed positive samples, as judged by the presence of corpuscles inside the red blood cells, suggestive of the presence of Bartonella spp (Fig. 3A). Microscopic analysis (1000X) suggested a low level of intracellular infection, with approximately $1 \%$ of the red blood cells being infected, which is similar to the value published by Mehock et al. (1998). However, the presence of intraeryth- rocytic corpuscles can only be considered presumptive for Bartonella infection, because false-positive results due to dye precipitates or artefacts cannot be excluded and, hence, further confirmation with other methods is imperative. Because no culture method is currently recommended as a gold standard for Bartonella isolation, in cases where infection by these agents is suspected, molecular detection methods, such as PCR, may be used to confirm or rule out the presence of these agents. For patients, especially those with some degree of immunosuppression, molecular methods could provide rapid diagnosis of bartonellosis and allow faster initiation of treatment, thus preventing other consequences of the disease.

In summary, our results showed that $B$. henselae and $B$. clarridgeiae are prevalent in cats in our region, representing $10.63 \%$ and $6.38 \%$ of the infectious cases, respectively, which is similar to the rates described in other countries. The species found here are those associated with CSD and, therefore, they may pose some risk to public health, mainly for HIV-positive individuals and for patients with rheumatic X (Lamas et al. 2007). The demonstration of the existence of this pathogen in cats in our region reinforces the importance of considering CSD in the differential diagnosis of patients with lymphadenopathy, abdominal pain, prolonged fever or other characteristic symptoms.

\section{ACKNOWLEDGEMENTS}

To the employers and volunteers of municipal shelters, for providing the animals for this study.

\section{REFERENCES}

Amaro MH, Dias F, Kataoka M, Barja J, Amaro JH 1996. Infiltrado retiniano na "cat scratch disease". Rev Bras Oftalmol 55: 791-794.

Anderson BE, Neuman MA 1997. Bartonella spp as emerging human pathogens. Clin Microbiol Rev 10: 203-219.

Angulo FJ, Glaser CA, Juranek DD, Lappin MR, Regnery RL 1994. Caring for pets of immunocompromised persons. J Am Vet Med Assoc 205: 1711-1718.

Arvand M, Klose AJ, Schwartz-Porsche D, Hahn H, Wendt C 2001. Genetic variability and prevalence of Bartonella henselae in cats in Berlin, Germany, and analysis of its genetic relatedness to a strain from Berlin that is pathogenic for humans. J Clin Microbiol 39: 743-746.

Bentzel DE, Espinosa BJ, Canal E, Blazes DL, Hall ER 2008. Susceptibility of owl monkeys (Aotus nancymaae) to experimental infection with Bartonella bacilliformis. Comp Med 58: 76-80.

Bergmans AM, de Jong CM, van Amerongen G, Schot CS, Schouls LM 1997. Prevalence of Bartonella species in domestic cats in The Netherlands. J Clin Microbiol 35: 2256-2261.

Billeter SA, Levy MG, Chomel BB, Breitschwerdt EB 2008. Vector transmission of Bartonella species with emphasis on the potential for tick transmission. Med Vet Entomol 22: 1-15.

Birtles RJ, Laycock G, Kenny MJ, Shaw SE, Day MJ 2002. Prevalence of Bartonella species causing bacteraemia in domesticated and companion animals in the United Kingdom. Vet Rec 151: 225-229.

Boulouis HJ, Chang CC, Henn JB, Kasten RW, Chomel BB 2005. Factors associated with the rapid emergence of zoonotic Bartonella infections. Vet Res 36: 383-410.

Breitschwerdt EB, Kordick DL 2000. Bartonella infection in animals: carriership, reservoir potential, pathogenicity and zoonotic potential for human infection. Clin Microbiol Rev 13: 428-438. 
Brenner SA, Rooney JA, Manzewitsch P, Regnery RL 1997. Isolation of Bartonella (Rochalimae) henselae: effects of methods of blood collection and handling. J Clin Microbiol 35: 544-547.

Carithers HA 1985. Cat-scratch disease. An overview based on a study of 1,200 patients. Am J Dis Child 139: 1124-1133.

Celebi B, Kilic S, Aydin N, Tarhan G, Carhan A, Babur C 2009. Investigation of Bartonella henselae in cats in Ankara, Turkey. Zoonoses Public Health 56: 169-175.

Chang CC, Chomel BB, Kasten RW, Romano V, Tietze N 2001. Molecular evidence of Bartonella spp in questing adult Ixodes pacificus ticks in California. J Clin Microbiol 39: 1221-1226.

Childs JE, Olson JG, Wolf A, Cohen N, Fakile Y, Rooney JA, Bacellar F, Regnery RL 1995. Prevalence of antibodies to Rochalimaea species (cat-scratch disease agent) in cats. Vet Rec 136: 519-520.

Chomel BB 2000. Cat-scratch disease. Rev Sci Tech 19: 136-150.

Chomel BB, Abbott RC, Kasten RW, Floyd-Hawkins KA, Kass PH, Glaser CA, Pedersen NC, Koehler JE 1995. Bartonella henselae prevalence in domestic cats in California: risk factors and association between bacteremia and antibody titers. J Clin Microbiol 33: $2445-2450$.

Chomel BB, Boulouis HJ, Petersen H, Kasten RW, Yamamoto K, Chang CC, Gandoin C, Bouillin C, Hew CM 2002. Prevalence of Bartonella infection in domestic cats in Denmark. Vet Res 33: 205-213.

Chomel BB, Carlos ET, Kasten RW, Yamamoto K, Chang CC, Carlos RS, Abenes MV, Pajares CM 1999. Bartonella henselae and Bartonella clarridgeiae infection in domestic cats from The Philippines. Am J Trop Med Hyg 60: 593-597.

Costa PSG, Brigatte ME, Greco DB 2005. Antibodies to Rickettsia rickettsii, Rickettsia typhi, Coxiella burnetii, Bartonella henselae, Bartonella quintana and Ehrlichia chaffeensis among healthy population in Minas Gerais, Brazil. Mem Inst Oswaldo Cruz 100: 853-859.

Cotté V, Bonnet S, Le Rhun D, Le Naour E, Chauvin A, Boulouis HJ, Lecuelle B, Lilin T, Vayssier-Taussat M 2008. Transmission of Bartonella henselae by Ixodes ricinus. Emerg Infect Dis 14: 1074-1080.

Curi AL, Machado DO, Heringer G, Campos WR, Orefice F 2006. Ocular manifestation of cat-scratch disease in HIV-positive patients. Am J Ophthalmol 141: 400-401.

Dehio C, Sander A 1999. Bartonella as emerging pathogens. Trends Microbiol 7: 226-228.

Diniz PP, Maggi RG, Schwartz DS, Cadenas MB, Bradley JM, Hegarty B, Breitschwerdt EB 2007. Canine bartonellosis: serological and molecular prevalence in Brazil and evidence of co-infection with Bartonella henselae and Bartonella vinsonii subsp. berkhoffii. Vet Res 38: 697-710.

Engvall EO, Brändström B, Fermér C, Blomqvist G, Englund L 2003. Prevalence of Bartonella henselae in young, healthy cats in Sweden. Vet Rec 152: 366-369.

Fabbi M, De Giuli L, Tranquillo M, Bragoni R, Casiraghi M, Genchi C 2004. Prevalence of Bartonella henselae in Italian stray cats: evaluation of serology to assess the risk of transmission of Bartonella to humans. J Clin Microbiol 42: 264-268.

Filoni C, Catão-Dias JL, Bay G, Durigon EL, Jorge RS, Lutz H, Hofmann-Lehmann R 2006. First evidence of feline Herpesvirus, Calicivirus, Parvovirus and Ehrlichia exposure in Brazilian freeranging felids. J Wildl Dis 42: 470-477.

Glaus T, Hofmann-Lehmann R, Greene C, Glaus B, Wolfensberger C, Lutz H 1997. Seroprevalence of Bartonella henselae infection and correlation with disease status in cats in Switzerland. $J$ Clin Microbiol 35: 2883-2885.
Gurfield AN, Boulouis HJ, Chomel BB, Kasten RW, Heller R, Bouillin C, Gandoin C, Thibault D, Chang CC, Barrat F, Piemont Y 2001. Epidemiology of Bartonella infection in domestic cats in France. Vet Microbiol 80: 185-198.

Heller R, Artois M, Xemar V, De Briel D, Gehin H, Jaulhac B, Monteil H, Piemont Y 1997. Prevalence of Bartonella henselae and Bartonella clarridgeiae in stray cats. J Clin Microbiol 35: 1327-1331.

Inoue K, Maruyama S, Kabeya H, Kawanami K, Yanai K, Jitchum S, Jittaparapong S 2009. Prevalence of Bartonella infection in cats and dogs in a metropolitan area, Thailand. Epidemiol Infect 137: $1568-1573$

Jacomo V, Kelly PJ, Raoult D 2002. Natural history of Bartonella infections (an exception to Koch's postulate). Clin Diagn Lab Immunol 9: 8-18.

Jensen WA, Fall MZ, Rooney J, Kordick DL, Breitschwerdt EB 2000. Rapid identification and differentiation of Bartonella species using a single-step PCR assay. J Clin Microbiol 38: 1717-1722.

Johnson G, Ayers M, McClure SC, Richardson SE, Tellier R 2003. Detection and identification of Bartonella species pathogenic for humans by PCR amplification targeting the riboflavin synthase gene (ribC). J Clin Microbiol 41: 1069-1072.

Kim YS, Seo KW, Lee JH, Choi EW, Lee HW, Hwang CY, Shin NS, Youn HJ, Youn HY 2009. Prevalence of Bartonella henselae and Bartonella clarridgeiae in cats and dogs in Korea. $J$ Vet Sci 10: 85-87.

Kimura M 1980. A simple method for estimating evolutionary rates of base substitutions through comparative studies of nucleotide sequences. J Mol Evol 16: 111-120.

Kordick DL, Breitschwerdt EB 1995. Intraerythrocytic presence of Bartonella henselae. J Clin Microbiol 33: 1655-1656.

Kordick DL, Hilyard EJ, Hadfield TL, Wilson KH, Steigerwalt AG, Brenner DJ, Breitschwerdt EB 1997. Bartonella clarridgeiae, a newly recognized zoonotic pathogen causing inoculation papules, fever and lymphadenopathy (cat scratch disease). J Clin Microbiol 35: 1813-1818.

La Scola B, Raoult D 1999. Culture of Bartonella quintana and Bartonella henselae from human samples: a 5-year experience (1993 to 1998). J Clin Microbiol 37: 1899-1905.

Lamas C, Curi A, Bóia MN, Lemos ERS 2008. Human bartonellosis: seroepidemiological and clinical features with an emphasis on data from Brazil - A review. Mem Inst Oswaldo Cruz 103: 221-235.

Lamas C, Favacho A, Ramos RG, Santos MS, Ferravoli GI, Weksler C, Rozental T, Bóia MN, Lemos ER 2007. Bartonella native valve endocarditis: the first Brazilian case alive and well. Braz J Infect Dis 11: 591-594.

Lamas CC, Mares-Guia MA, Rozental T, Moreira N, Favacho AR, Barreira J, Guterres A, Bóia MN, de Lemos ER 2010. Bartonella spp infection in HIV positive individuals, their pets and ectoparasites in Rio de Janeiro, Brazil: serological and molecular study. Acta Trop 115: 137-141.

Leighton FA, Artsob HA, Chu MC, Olson JG 2001. A serological survey of rural dogs and cats on the southwestern Canadian prairie for zoonotic pathogens. Can J Public Health 92: 67-71.

Maco V, Maguiña C, Tirado A, Maco V, Vidal JE 2004. Carrion's disease (Bartonellosis bacilliformis) confirmed by histopathology in the High Forest of Peru. Rev Inst Med Trop Sao Paulo 46: 171-174.

Maguiña C, Garcia PJ, Gotuzzo E, Cordero L, Spach DH 2001. Bartonellosis (Carrion's disease) in the modern era. Clin Infect Dis 33: 772-779. 
Marston EL, Finkel B, Regnery RL, Winoto IL, Graham RR, Wignal S, Simanjuntak G, Olson JG 1999. Prevalence of Bartonella henselae and Bartonella clarridgeiae in an urban Indonesian cat population. Clin Diagn Lab Immunol 6: 41-44.

Maruyama S, Hiraga S, Yokoyama E, Naoi M, Tsuruoka Y, Ogura Y, Tamura K, Namba S, Kameyama Y, Nakamura S, Katsube Y 1998. Seroprevalence of Bartonella henselae and Toxoplasma gondii infections among pet cats in Kanagawa and Saitama prefectures. J Vet Med Sci 60: 997-1000.

Mehock JR, Greene CE, Gherardini FC, Hahn TW, Krause DC 1998. Bartonella henselae invasion of feline erythrocytes in vitro. Infect Immun 66: 3462-3466.

Melter O, Hercík K, Weyant RS, Janecek J, Nemec A, Mecera J, Gonzorová L, Branny P 2003. Detection and characterization of feline Bartonella henselae in the Czech Republic. Vet Microbiol 93: $261-273$

Nasirudeen AM, Thong ML 1999. Prevalence of Bartonella henselae immunoglobulin G antibodies in Singaporean cats. Pediatr Infect Dis J 18: 276-278.

Podsiadly E, Sokolowska E, Tylewska-Wierzbanowska S 2003. Seroprevalence of Bartonella henselae and Bartonella quintana infections in Poland in 1998-2001. Ann NY Acad Sci 990: 407-408.

Rolain JM, Locatelli C, Chabanne L, Davoust B, Raoult D 2004. Prevalence of Bartonella clarridgeiae and Bartonella henselae in domestic cats from France and detection of the organisms in erythrocytes by immunofluorescence. Clin Diagn Lab Immunol 11: $423-425$
Saitou N, Nei M 1987. The neighbor-joining method: a new method for reconstructing phylogenetic trees. Mol Biol Evol 4: 406-425.

Sander A, Bühler C, Pelz K, von Cramm E, Bredt W 1997. Detection and identification of two Bartonella henselae variants in domestic cats in Germany. J Clin Microbiol 35: 584-587.

Slhessarenko N, Camargo MCGO, D'auria SRN 1996. Soroprevalência de Bartonella henselae em gatos do município de São Paulo. Rev Soc Bras Med Trop 29: 104-110.

Souza AM 2009. Freqüência de infecção por Bartonella spp e alterações sangüineas em gatos domésticos no estado do Rio de Janeiro-Brasil, $\mathrm{PhD}$ Thesis, Universidade Federal Fluminense, Rio de Janeiro, 98 pp.

Spach DH, Kanter AS, Dougherty MJ, Larson AM, Coyle MB, Brenner DJ, Swaminathan B, Matar GM, Welch DF, Root RK, Stamm WE 1995. Bartonella (Rochalimaea) quintana bacteremia in inner-city patients with chronic alcoholism. $N$ Engl J Med 332: 424-428.

Spach DH, Koehler JE 1998. Bartonella-associated infections. Infect Dis Clin North Am 12: 137-155.

Tamura K, Dudley J, Nei M, Kumar S 2007. MEGA4: Molecular Evolutionary Genetics Analysis (MEGA) software version 4.0. Mol Biol Evol 24: 1596-1599.

Zangwill KM, Hamilton DH, Perkins BA, Regnery RL, Plikaytis BD, Hadler JL, Cartter ML, Wenger JD 1993. Cat scratch disease in Connecticut. Epidemiology, risk factors, and evaluation of a new diagnostic test. $N$ Engl J Med 329: 8-13. 